\title{
Meta-Analysis of NOS3 G894T Polymorphisms with Air Pollution on the Risk of Ischemic Heart Disease Worldwide
}

\author{
Robin Johns ${ }^{1}$, Zhao-Feng Chen ${ }^{2}$, Lufei Young ${ }^{1}$ (D), Flordelis Delacruz ${ }^{3}$, Nien-Tzu Chang ${ }^{4}$ (D), \\ Chong Ho Yu ${ }^{5}$ and S. Pamela K. Shiao ${ }^{1,6, * \text { id }}$ \\ 1 College of Nursing, Augusta University, 987 St. Sebastian Way, EC 4505, Augusta, GA 30912, USA; \\ rjohns@augusta.edu (R.J.); luyoung@augusta.edu (L.Y.) \\ 2 Department of Nursing, Yuanpei University of Medical Technology No. 306, Yuanpei Street, \\ 30015 Hsinchu, Taiwan; ivan.chen1966@gmail.com \\ 3 Department of Nursing, National University, San Diego, CA 92127, USA; delacruzflordelis@yahoo.com \\ 4 School of Nursing, National Taiwan University, Taipei 10051, Taiwan; ntchang@ntu.edu.tw \\ 5 Department of Psychology, Azusa Pacific University, Azusa, CA 91702, USA; cyu@apu.edu \\ 6 Medical College of Georgia, Augusta University, Augusta, GA 30912, USA \\ * Correspondence: pshiao@msn.com; Tel.: +1-818-233-6112
}

Received: 1 June 2018; Accepted: 27 July 2018; Published: 1 August 2018

\begin{abstract}
The purpose of this updated meta-analysis was to investigate the effect of nitric oxide synthase-3 (NOS3) G894T polymorphisms, air pollution and their interaction on ischemic heart disease (IHD) risk across populations worldwide. Recursive partition trees, nonlinear association curve fit and geographic information system maps were incorporated to verify results of conventional pooled analyses for sources of heterogeneity. Results from 61 studies (16,219 cases, 12,222 controls) revealed a significant increased relative risk (RR) of IHD associated with NOS3 894 polymorphisms $\mathrm{TT}(\mathrm{RR}=1.44)$ and GT $(\mathrm{RR}=1.37)$. Subgroup analysis revealed that the TT polymorphism genotype had significantly increased risk of IHD in Caucasian, East Asian, South Asian, and Middle Eastern populations (all $p<0.05$ ). It is important to point out that many countries demonstrated an average risk of greater than two, which identifies the NOS3 894 TT polymorphism as a potential causal factor and biological marker of IHD, based on criteria for strong evidence used in international consensus panels. These 10 countries include Ukraine, the United Kingdom, Brazil, Chile, Japan, South Korea, India, Iran, Egypt and Morocco. For these countries with elevated risk (RR > 2) from the NOS3 894 TT polymorphism, meta-predictive analysis demonstrated an increasing trend in air pollution association with increased NOS3 894 polymorphisms. Further studies are needed to explore the complexity of the associations among NOS3 gene polymorphisms per population stratifications within countries, detailed air pollution data for added specificity for geographic location across time, and disease risk.
\end{abstract}

Keywords: meta-analysis; NOS3 G894T gene; ischemic heart disease; cardiovascular disease

\section{Introduction}

Ischemic heart disease (IHD) is the leading cause of death and a major economic burden worldwide. It is the cause of over $30 \%$ of total annual deaths [1-4] and constitutes $17 \%$ of overall national health expenditure in the United States (U.S.) [5]. It is projected that by 2035, IHD will affect 131.2 million Americans (45 percent of the total U.S. population) with an annual cost of $\$ 1.1$ trillion, resulting in a crushing impact on the nation's financial and health care systems [6]. Many epidemiological studies have revealed substantial evidence of genetic components (ranging 
from $20-60 \%$ ) that contribute toward the progression of IHD; however, etiologic pathways associated with gene polymorphisms and the risk of IHD remain unclear $[7,8]$.

Endothelial-derived nitric oxide (NO) is a powerful vasodilator with known vasoprotective effects, and its physiologic functions are as follows: (1) vascular relaxation; (2) platelet suppression; (3) decreased leucocyte adhesion to the vascular endothelium; (4) reduced smooth muscle cell proliferation and migration [9-12]; and (5) reduction of atherogenic low density lipoprotein oxidation [12]. NO is synthesized from L-arginine by nitric oxide synthase-3 (NOS3), a protein coding gene located on chromosome 7q35-36 [11]. Variations in this gene are associated with susceptibility to coronary spasm and are known to have a major effect in the development of atherothrombogenesis [13]. The single nucleotide polymorphism (SNP) NOS3 894GT located in exon 7 (also known as Glu298Asp, rs1799983) is a genetic marker that has been specifically linked to an increased risk of IHD, hypertension, coronary spasms, and stent re-stenosis $[8,14,15]$. The NOS3 894GT SNP represents a guanine (G)/thymine (T) substitution at position 894 on exon 7 leading to a change from glutamate to aspartate at position 298; rs1799983 [11]. NOS3 activity is reduced in the presence of the T allele for NOS3 G894T polymorphisms [16], with previous meta-analyses confirming the association of NOS3 G894T with the development of IHD among various ethnicities and disease subgroups [12,17-21].

Likewise, there are several epidemiologic studies suggesting the incidence of IHD morbidity and mortality may be related to exposure to ambient pollutants that trigger the development of IHD [22-29]. Many studies examining gene-environment interactions have found air pollution may be involved in modifying genetic variants and associated disease risk [30-42] as well as levels of inflammatory markers and subsequent risk of myocardial infarction (MI) [43]. Thus, there is evidence that associations of air pollution with gene markers for cardiovascular risk are mediated by oxidative stress pathways. Inhalation of airborne particulate matter (PM) inhibits both nitric oxide synthase activity and nitric oxide release, resulting in vasoconstriction [38,41]. Oxidative stress induced by PM-dependent reactive oxygen species (ROS) production affects vascular function by disrupting endothelial function; and PM exposure has been demonstrated to potentiate hypertension through NOS-dependent ROS generation [42]. In addition, investigation of associations of air pollution exposure with blood pressure and heart rate variability revealed both are modified by gene polymorphisms in the oxidative stress pathways, including NOS3 [37]. Because NOS3 affects metabolism in the urea cycle of the methylation pathway, which is critical for preventing systemic inflammation as an epigenetic risk factor for heart health, it is important to explore associations among NOS3 894 gene polymorphisms, air pollution, and IHD [44-47].

Therefore, the purpose of this updated meta-analysis is to examine the association of NOS3 894 polymorphisms as risk factors for IHD, using meta-predictive analytics to investigate the source of heterogeneity, including air pollution for IHD susceptibility. This study is the most comprehensive meta-analysis to date on the impact of NOS3 894 on IHD. The gaps in knowledge were filled that were not addressed in previously published meta-analyses which focused only on sub-populations (Asians) and sub-types of IHD.

\section{Materials and Methods}

\subsection{Search Strategy and Selection Criteria}

Online databases of PubMed, PubMed Central and Google Scholar were searched for all available studies from 1998 (publication year of first related study) through September 2017 following the guidelines for preferred reporting of items for meta-analysis of observational studies [48-50]. The search was conducted using the following keywords and subject terms: NOS3 894, ischemic heart disease, coronary heart disease, meta-analysis, case-control, and was limited to human studies. In addition, previous meta-analyses and review papers were used to cross reference and trace back to all original studies. Databases were searched repeatedly every three months for a total of four different 
times to identify any new papers. Two investigators were responsible for conducting the literature search and recording data. Studies published in other languages or from other countries were included, but only if they included both an abstract in English and tables clearly listing genotype allele counts. Studies lacking genotypes for case and controls or appropriate genotype allele counts were excluded.

Two hundred and forty-two relevant studies were initially identified, with 106 subsequently excluded because they did not have genotypes for case and controls and/or genotype allele counts. The 136 remaining studies were retrieved for evaluation. Of those, 34 studies were further excluded due to no English abstract and/or no appropriate genotype allele counts. The remaining 102 studies were retrieved for further evaluation, of which 49 studies were further eliminated due to no clear genotype counts. Further searches resulted in the identification of eight additional usable studies from a list of 30 studies. Thus, a total of 61 studies were included in the final meta-analysis (Figure 1).

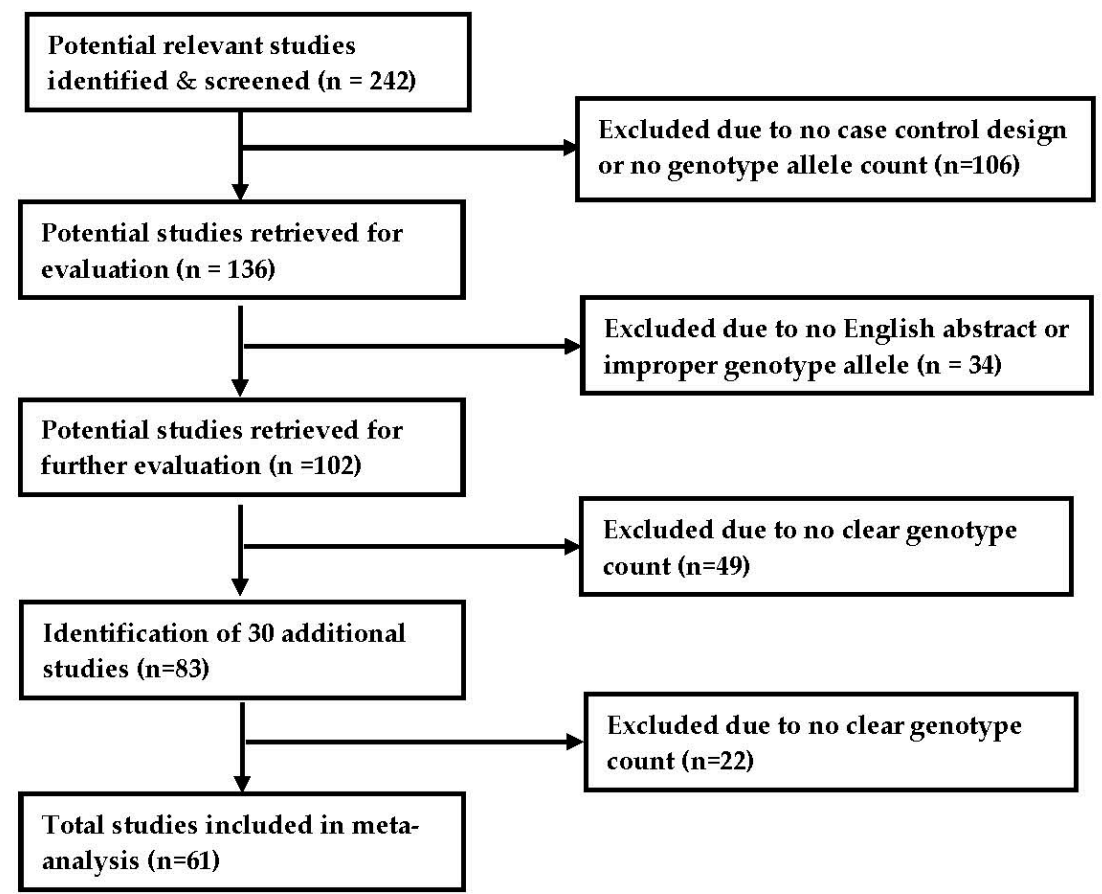

Figure 1. Progression of the selection of studies for the meta-analysis.

\subsection{Characteristics of Included Studies}

Study populations were drawn from Australia, Europe, Central America, South America, Asia, the Middle East, and Africa. The majority of populations from these studies were Caucasian (25) and East Asian (18) studies, followed by South Asian (six), African (six), Middle Eastern (four), and Hispanic (two) (Supplementary Table S1). The air pollution markers we used is per country data, because the source data from each original study were reported per countries and missing specific locations within the country. While we attempted to examine specific locations for each country per study, many studies did not report specific locations within each country. Further scale for geographic location per country would yield missing data and insufficient numbers for meta-analysis. Air-quality data was entered for all countries. Specifically, we verified the most current and complete air-pollution data including the death rates from air pollution (death rates per million, Level 1: <50, Level 2: 51-100, Level 3: 101-250, Level 4: 251-400, Level 5: $\geq 401$ ) [51-53]. Current scales on air pollution data were used to further verify these levels [54-56], and the most complete and current data on air pollution was used for the analyses. There was only one study (Ireland) with a Level 1 air pollution death rate (AP death) level and one study (Ukraine) with a Level 5; therefore, Level 1 was merged with Level 2 and Level 5 was merged with Level 4 for the final analysis. 


\subsection{Quality Assessment}

Data including genotype allele counts and quality scores were checked for accuracy by three team members; for discrepancies, a consensus was reached by involving a fourth team member based on the criteria for quality in published meta-analyses (PRISMA) and other observational studies [30,49,50]. The quality scores for included studies ranged from 10 to 25 (possible score range of 0-29). For the representative DNA analysis, Hardy Weinberg Equilibrium (HWE) analyses were checked for all studies, which were developed to assess the distribution equilibrium for evolutionary mechanisms associated with population genetics $[57,58]$. Characteristics of all included original studies on NOS3 894 genotypes are reported in Supplementary Table S1.

\subsection{Data Synthesis and Analysis}

Genotype allele counts, along with all other data, were entered into Excel (Microsoft Corp, Redmond, WA, USA), and pooled using Stats Direct Version 3.1.4 (Cheshire, UK). Pooled risk ratios (RR) for NOS3 894 genotypes for cases and controls and 95\% confidence intervals (CI) were calculated for the associations of polymorphisms and IHD with heterogeneity tested before selection of an association model. Pooled RRs are preferred to odds ratios (OR) according to related consensus reports for the field of study $[30,59,60]$; they have been demonstrated to be more robust and better for comparison due to standardization of the denominator as opposed to using only one genotype as the denominator [30-35,59-63]. We used total counts of all three NOS3 894 genotypes (homozygous TT, heterozygous GT, and wild-type GG genotypes) as the denominators to compute standardized ratios for RRs. Thus, a pooled RR of greater than one represents an increased risk for IHD among gene variations, whereas a pooled RR less than one indicates a protective effect (favoring the case or the IHD group). Significant findings were identified at a value of $p<0.05$.

Additionally, because the data presented heterogeneity with some regional differences on polymorphism rates and risks, the JMP 13 Pro program (SAS Institute, 2016) was used to generate geographic information system (GIS) maps to depict global gene polymorphism patterns and IHD risks, allowing visual identification of geographic patterns [64]. JMP is a statistical program for data visualization, exploratory data analysis, and data mining, and these features are instrumental to this study. Furthermore, meta-prediction analysis using JMP 13 Pro was incorporated to examine how AP death (independent variable) decisively split the dependent variable data (polymorphism genotype frequencies and IHD risks) [30]. Meta-prediction methods integrated multiple statistical models for triangulation purposes $[30,65]$. Through triangulation, sources of heterogeneity were explored and identified for divergent NOS3 894 polymorphism rates and IHD risk; GIS maps were generated to manage the geospatial data set and help associate regional patterns of polymorphisms and IHD risk with AP death by country [30,64]. Recursive partition analysis using JMP 13 Pro was incorporated to create a decision tree that classified groups of population (NOS3 894 polymorphism rates in cases and control groups and risks) by splitting data into subgroups based on levels of AP death $[30,33,66]$. We used AP death instead of air pollution or air quality index because without indicating the outcome (death), air quality index alone could be misleading. Prior research had suggested that PM can endanger public health when varying weather conditions are taken into account [67]. In other words, the risks of respiratory and circulatory system diseases increase when the effects of certain weather conditions are present. However, the weather characteristics associated with PM have not been thoroughly studied [68], and thus we chose an outcome-based index (AP death) instead.

To provide consistency with other meta-analyses and allow for easy comparison, we also employed a conventional multiple comparison procedure (Tukey's test) [69] to examine whether meta-predictive data analytics (recursive partition trees) and Tukey's tests concurred with each other when examining the interaction between gene mutation and air pollution (AP), and its prediction on IHD risk [33]. The advantage of meta-prediction over conventional statistical methods (meta-regression) is that these analytics (e.g., recursive partition trees) are useful in verifying results by cross validation [70-72] and enhance sensitivity and specificity [73], and thus may yield more accurate 
meta-predictive results [74]. Akaike's Information Criterion (AIC) was employed for selecting the optimal number of subgroups, from which the model yielding the smallest AIC value is utilized [75] Finally, we also used a nonlinear fit curve to examine the associations between AP death and the polymorphism genotype percentage and IHD risks. By integrating data from diverse sources, advanced techniques including recursive partition trees and nonlinear fit are able to predict more accurately and precisely, thus strengthening our analysis. While meta-regression is used commonly for advanced meta-analysis for meta-prediction [63], it is important to point out that regression analysis, as a linear model, is unable to detect nonlinear patterns. In this study, we performed meta-prediction using recursive partition trees, nonlinear fit, and heat maps for data visualization to reveal nonlinear patterns. Further, it is well known that regression based on $\mathrm{R}^{2}$ tends to yield a complex and over-fitted model because $R^{2}$ always goes up with additional predictors. On the other hand, AIC or Akaike's information criterion correction (AICc) does not necessarily change with the addition of variables. Rather, it varies based upon the composition of the predictors; thus, it is more likely to yield an optimal model [76].

\section{Results}

\subsection{Pooled Meta-Analysis}

Pooled analysis of NOS3 genotypes from 61 studies with genotypes for case and controls was used to identify the association of NOS3 894 gene variations with IHD in global populations. The analysis included a total of 16,219 IHD cases and 12,222 controls (Table 1). The GG wild genotype ( $53.1 \%$ cases and $60.8 \%$ controls) presented as the most frequent genotype across all populations and was found to be protective against IHD for all racial-ethnic groups $(\mathrm{RR}=0.92, p<0.0001)$. The heterozygous GT polymorphism genotype ( $37.4 \%$ cases and $32.4 \%$ controls) was associated with an increased risk of IHD for all groups ( $R R=1.37, p<0.0001)$. The homozygous TT polymorphism genotype $(9.5 \%$ cases and $6.2 \%$ controls) presented the least frequently, and, like the GT polymorphism, was associated with an increased risk of IHD for all groups $(R R=1.44, p<0.0001)$. Furthermore, the $\mathrm{T}$ allele was associated with an increased risk of IHD for all groups combined $(R R=1.18, p<0.0001)$. In contrast, the $\mathrm{G}$ allele was found to be protective against IHD for all racial-ethnic groups ( $R R=0.95, p<0.0001$ ). Homozygous TT polymorphism percent distributions were observed to be higher in Caucasians $(10.2 \%)$ than in African (8.0\%), Hispanic (4.4\%), Middle Eastern (4.2\%), South Asian (2.0\%) and East Asian groups $(0.7 \%)$, in the control groups as the basis for healthy populations. GT polymorphism percent distributions were observed to be higher in Caucasians (43.6\%) than in African (38.2\%), Hispanic (32.8\%), Middle Eastern (30.6\%), South Asian (24.4\%) and East Asian groups (14.6\%), in the control groups as the basis for healthy populations. Similar distinctive patterns were noted for the IHD cases across all of the racial-ethnic groups. Supplementary Figure S1 presents the percent homozygous TT and heterozygous GT genotypes for the countries included in the analyses. When visualizing forest plots for the meta-analysis, most studies presented both NOS3 894 TT and GT genotypes as risk genotypes (RR $>1$ ) of IHD. Racial-ethnic subgroup analysis revealed that the homozygous TT genotype was associated with an increased risk of IHD in Caucasian $(p=0.0051)$, East Asian $(p<0.0001)$, South Asian $(p=0.0076)$, and Middle Eastern $(p=0.0003)$ populations. The heterozygous GT genotype was also associated with an increased risk of IHD for both East Asian $(p<0.0001)$ and South Asian $(p=0.0304)$ populations. 
Table 1. Pooled meta-analysis: NOS3 G894T genotypes and risk for ischemic heart disease (IHD).

\begin{tabular}{|c|c|c|c|c|c|}
\hline \multirow{2}{*}{$\frac{\text { Genotype }}{\text { (Number of Studies) }}$} & \multirow{2}{*}{$\begin{array}{c}\text { Cases } \\
n=16,219(\%)\end{array}$} & \multirow{2}{*}{$\begin{array}{c}\text { Controls } \\
n=12,222(\%)\end{array}$} & \multicolumn{3}{|c|}{ Tests of Association } \\
\hline & & & Model & RR (95\% CI) & $p$ \\
\hline TT (61) & $1551(9.56)$ & $759(6.21)$ & Random & $1.44(1.23,1.67)$ & 0.0001 \\
\hline Caucasian (25) & $1230(12.30)$ & $593(10.21)$ & Random & $1.30(1.08,1.56)$ & 0.0051 \\
\hline Hispanic (2) & $33(6.00)$ & $17(4.43)$ & Fixed & $1.34(0.76,2.34)$ & 0.3044 \\
\hline East Asian (18) & $79(2.60)$ & $26(0.74)$ & Fixed & $2.17(1.46,3.25)$ & 0.0001 \\
\hline South Asian (6) & $40(4.16)$ & $18(2.08)$ & Fixed & $2.11(1.21,3.65)$ & 0.0076 \\
\hline Middle East (4) & $65(9.31)$ & $25(4.26)$ & Fixed & $2.35(1.47,3.74)$ & 0.0003 \\
\hline African (6) & $104(10.54)$ & $80(8.06)$ & Random & $1.45(0.87,2.41)$ & 0.1457 \\
\hline GT (61) & $6066(37.40)$ & $3971(32.49)$ & Random & $1.37(1.18,1.57)$ & 0.0001 \\
\hline Caucasian (25) & $4271(42.71)$ & $2538(43.69)$ & Random & $0.96(0.91,1.02)$ & 0.2571 \\
\hline Hispanic (2) & $175(31.81)$ & $126(32.81)$ & Fixed & $0.96(0.79,1.16)$ & 0.6801 \\
\hline East Asian (18) & $672(22.12)$ & $518(14.66)$ & Random & $1.38(1.19,1.59)$ & 0.0001 \\
\hline South Asian (6) & $286(29.79)$ & $229(26.44)$ & Fixed & $1.17(1.01,1.36)$ & 0.0304 \\
\hline Middle East (4) & $272(38.96)$ & $180(30.61)$ & Random & $1.25(0.92,1.70)$ & 0.1388 \\
\hline African (6) & $390(39.55)$ & $380(38.27)$ & Random & $1.02(0.83,1.26)$ & 0.8032 \\
\hline GG (61) & $8613(53.10)$ & $7442(60.89)$ & Random & $0.92(0.89,0.95)$ & 0.0001 \\
\hline Caucasian (25) & $4498(44.98)$ & 2677 (46.09) & Random & $0.95(0.89,1.01)$ & 0.139 \\
\hline Hispanic (2) & $342(62.18)$ & $241(62.76)$ & Fixed & $0.99(0.89,1.10)$ & 0.9341 \\
\hline East Asian (18) & $2286(75.27)$ & $2989(84.60)$ & Random & $0.91(0.87,0.95)$ & 0.0001 \\
\hline South Asian (6) & $634(66.04)$ & $619(71.48)$ & Random & $0.97(0.84,1.13)$ & 0.7656 \\
\hline Middle East (4) & $361(51.72)$ & $383(65.14)$ & Fixed & $0.77(0.70,0.85)$ & 0.0001 \\
\hline African (6) & $492(49.90)$ & $533(53.68)$ & Random & $0.91(0.76,1.07)$ & 0.2809 \\
\hline $\mathrm{TT}+\mathrm{GT}(61)$ & 7617 (46.96) & $4730(38.70)$ & Random & $1.15(1.09,1.22)$ & 0.0001 \\
\hline Caucasian (25) & $5501(55.01)$ & 3131 (53.90) & Random & $1.03(0.98,1.09)$ & 0.176 \\
\hline Hispanic (2) & $208(37.81)$ & $143(37.24)$ & Fixed & $1.00(0.85,1.19)$ & 0.9339 \\
\hline East Asian (18) & $751(24.73)$ & $544(15.40)$ & Random & $1.44(1.26,1.64)$ & 0.0001 \\
\hline South Asian (6) & $326(33.96)$ & $247(28.52)$ & Fixed & $1.24(1.08,1.43)$ & 0.0018 \\
\hline Middle East (4) & $337(48.28)$ & $205(34.86)$ & Fixed & $1.42(1.24,1.63)$ & 0.0001 \\
\hline African (6) & $494(50.10)$ & $460(46.32)$ & Random & $1.10(0.92,1.33)$ & 0.2638 \\
\hline $\mathrm{T}$ allele (61) & $4585(28.20)$ & $2744(22.5)$ & Random & $1.18(1.11,1.25)$ & 0.0001 \\
\hline Caucasian (25) & $3366(33.66)$ & $1862(32.05)$ & Random & $1.07(1.00,1.16)$ & 0.0466 \\
\hline Hispanic (2) & $120(21.82)$ & $80(20.83)$ & Fixed & $1.04(0.81,1.34)$ & 0.7399 \\
\hline East Asian (18) & 415 (13.66) & $285(8.06)$ & Fixed & $1.48(1.28,1.71)$ & 0.0001 \\
\hline South Asian (6) & $183(19.06)$ & $132(15.24)$ & Fixed & $1.30(1.06,1.60)$ & 0.0106 \\
\hline Middle East (4) & $201(28.80)$ & 115 (19.56) & Fixed & $1.52(1.24,1.87)$ & 0.0001 \\
\hline African (6) & $299(30.32)$ & $270(27.19)$ & Fixed & $1.10(0.95,1.26)$ & 0.1743 \\
\hline G allele (61) & $11646(71.80)$ & $9428(77.2)$ & Random & $0.95(0.93,0.97)$ & 0.0001 \\
\hline Caucasian (25) & $6634(66.34)$ & $3946(67.94)$ & Random & $0.96(0.92,0.99)$ & 0.0304 \\
\hline Hispanic (2) & $429(78.00)$ & 304 (79.17) & Fixed & $0.98(0.92,1.05)$ & 0.7404 \\
\hline East Asian (18) & $2622(86.34)$ & $3248(91.93)$ & Fixed & $0.95(0.93,0.97)$ & 0.0001 \\
\hline South Asian (6) & $777(80.94)$ & $734(84.76)$ & Random & $1.02(0.89,1.16)$ & 0.7493 \\
\hline Middle East (4) & $497(71.20)$ & $473(80.44)$ & Fixed & $0.87(0.82,0.93)$ & 0.0001 \\
\hline African (6) & $687(69.68)$ & $723(72.81)$ & Fixed & $0.96(0.90,1.01)$ & 0.1761 \\
\hline
\end{tabular}

Note: $\mathrm{CI}$ = confidence interval; $\mathrm{RR}$ = risk ratio. Random effects models were used when $Q$ or $I^{2}$ were significant; otherwise, fixed effects models were used.

\subsection{Subgroup Analysis}

Subgroup analyses were conducted to explore the significant heterogeneity across regions for the NOS3 894 TT genotype split by countries that demonstrated a risk type (RR > 1-2, RR > 2) and countries with a protective type $(R R<1)$ (Figure 2, Supplementary Table S2, Supplementary Figures S2 and S3). Subgroup analysis allowed for stratification of TT risk (TT risk greater than 2, TT risk between 1-2, and TT risk less than 1) and revealed 10 countries with a TT risk $>2$ : Ukraine, the United Kingdom, Brazil, Chile, Japan, South Korea, India, Iran, Egypt, and Morocco (Figure 2); nine countries with a TT risk > 1-2: Turkey, Greece, Italy, Finland, Germany, Ireland, Mexico, China, and Saudi Arabia (Supplementary Figure S1); and four countries with a TT risk < 1: Australia, The Netherlands, Poland, 
and Tunisia (Supplementary Figure S3). When visualizing forest plots by RR subgroups, it was revealed that Ukraine, the United Kingdom, Brazil, Chile, Japan, South Korea, India, Iran, Egypt and Morocco presented the NOS3 894 TT genotype as a potential causal factor of IHD [59-62] (Figure 2). In contrast, the NOS3 894 TT genotype was protective for Australia, the Netherlands, Poland and Tunisia (Supplementary Figure S3).

\section{Relative risk meta-analysis plot (fixed effects)}

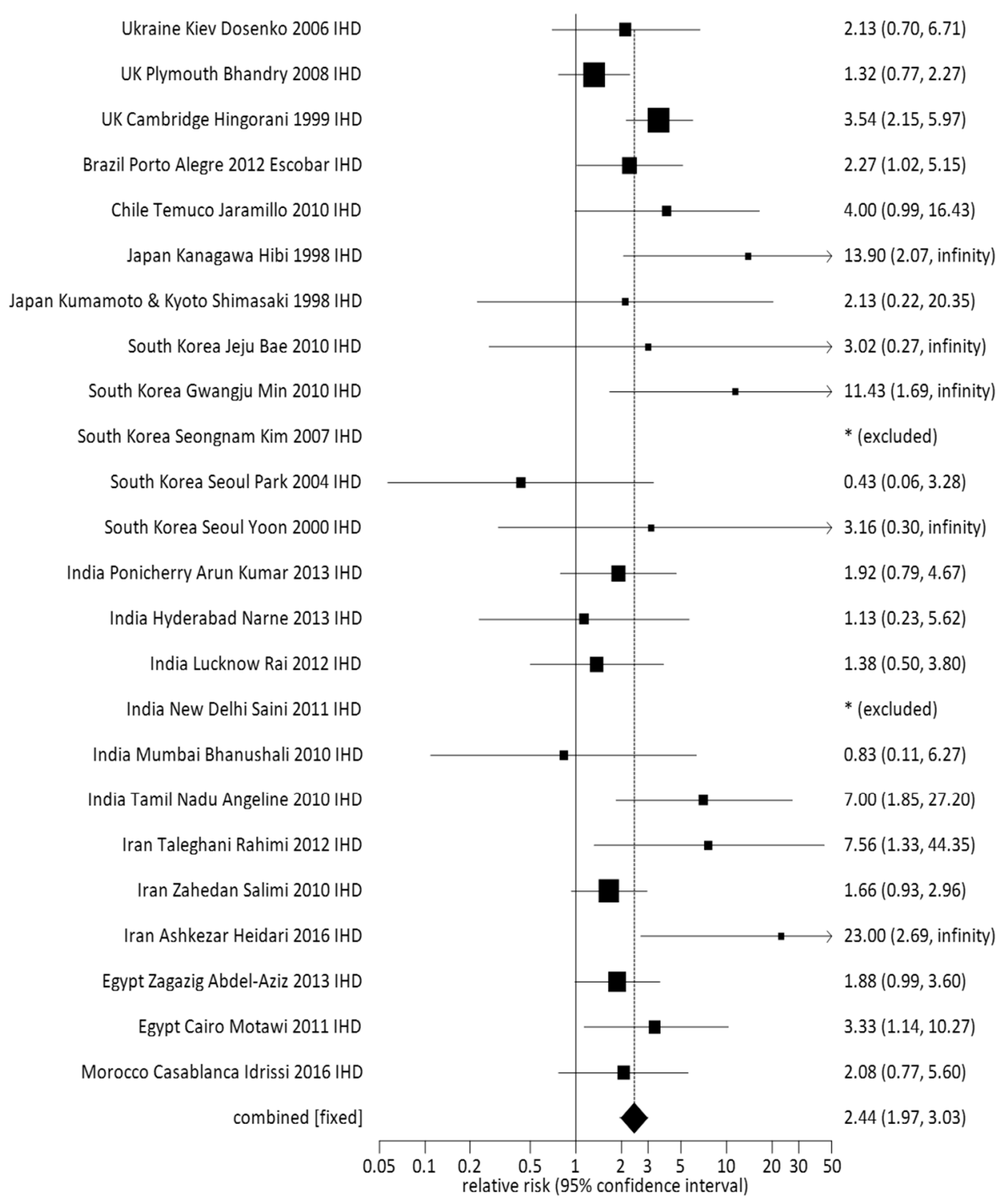

Figure 2. Forest plot for countries with pooled relative risk $(\mathrm{RR})>2$ for the meta-analysis of the association between the NOS3 TT genotype and ischemic heart disease (IHD). The midpoint = point effect estimate for each study. The area of the box = weight given to the study. The length of the line $=95 \%$ confidence interval for the effect estimate in an individual study. The width of the diamond $=95 \%$ confidence interval for the overall effect estimate. Note * (excluded): study excluded due to no TT genotypes reported for case/control groups.

The incorporation of GIS maps allowed for further illustration of NOS3 894 polymorphism rates and IHD risk association and enabled visual detection of regional patterns. The GIS maps graphically depict the highest total percent of NOS3 894 TT and GT genotypes for both control and cases groups in Caucasian nations (Figure 3, Supplementary Figures S4 and S5). However, the highest risks of IHD 
from NOS3 894 TT and GT polymorphisms were in East Asian and South Asian nations (Figure 3, Supplementary Figures S4 and S5). For individual NOS3 894 TT and GT polymorphisms, similar patterns were also demonstrated (Supplementary Figures S4 and S5). RRs were presented using a chromatic color spectrum with the red color representing IHD risk and the green color representing protective effects. Regions with the highest risk of combined NOS3 894 TT and GT genotypes were observed as Asia and Africa, followed by South America, then Europe (Figure 3). A similar pattern was observed for both individual NOS3 894 TT and GT genotypes (Supplementary Figures S4 and S5).
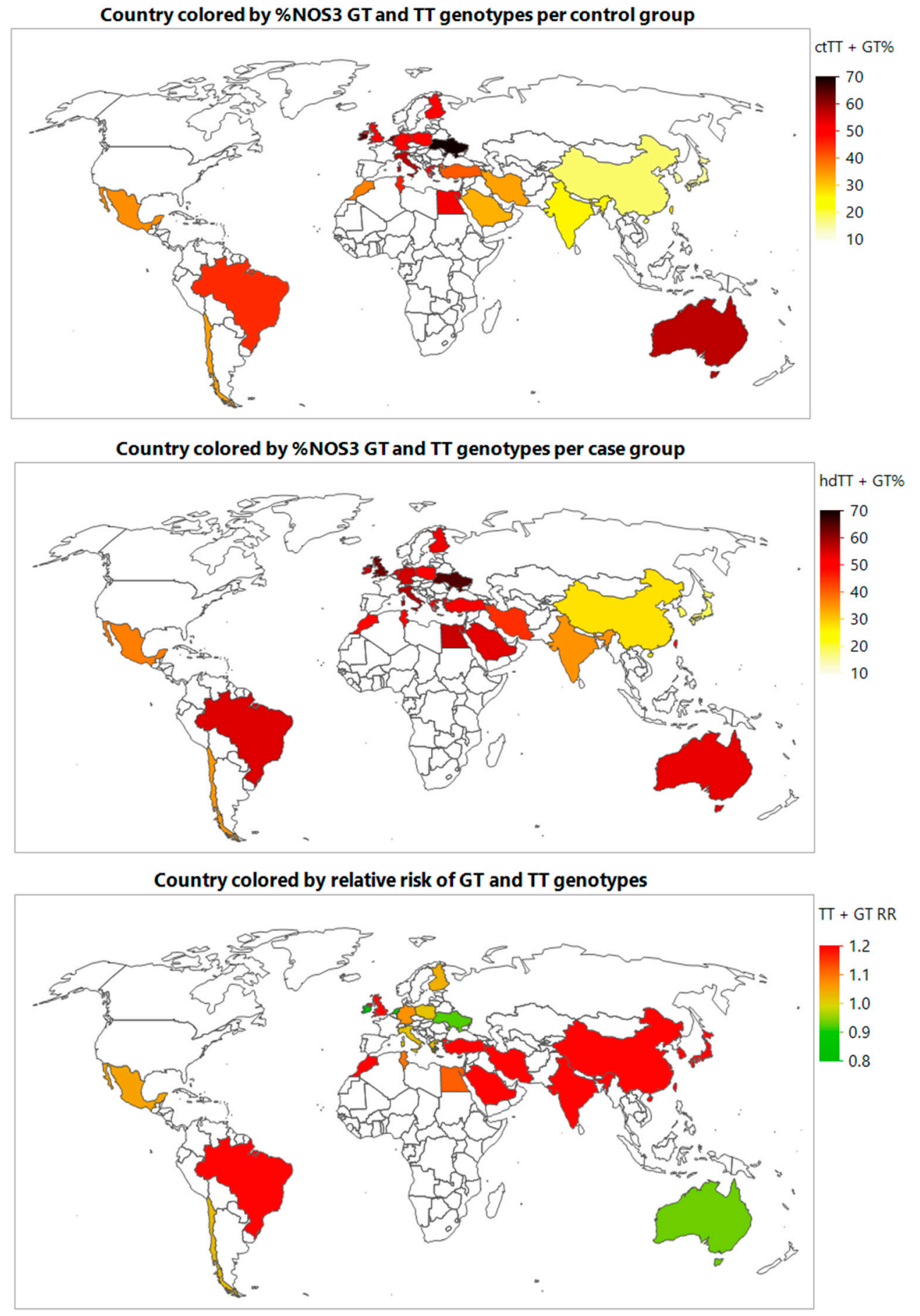

Figure 3. Geographical information map for \% NOS3 GT and TT genotypes per control and ischemic heart disease (IHD) groups, and IHD risk. 


\subsection{Meta-Prediction}

Meta-prediction analytics were incorporated to explore air pollution death rates for each country as possible contributing variables to NOS3 894 SNP percentages and risks for IHD. Partition tree analyses and Tukey's tests were used to test both variables. For partition trees, Akaike's information criterion correction (AICc) was used to select the best model with good fit to the truth with simplicity and parsimony $[30,74]$. The partition tree split the data into two groups by annual AP death rate levels (Levels $2=51-100,3=101-250,4=251-400$ death $/$ million populations). While no statistical significance was found, this analysis revealed a trend in the association among air pollution death rates, NOS3 894 polymorphisms and heart disease. Nonlinear association methods were used to explore the association between AP death and the NOS3 percentage of polymorphisms (Supplementary Figure S6) for both groups with TT plus GT polymorphisms (Supplementary Figure S6a) and TT polymorphism only (Supplementary Figure S6b. With a change in air pollution death rates from Level 3 to Level 4 using Tukey's tests, there was a upward trend in the percentage of NOS3 894 polymorphisms with an even more substantial increase in this trend for countries with a RR greater than 2 (Figure 4a for TT plus GT polymorphisms, Figure $4 \mathrm{~b}$ for TT polymorphism only, bi-variate plots). For the 10 countries with a TT risk > 2, Brazil, India, and Morocco presented AP death Level 2; Chile, South Korea, Iran, and Egypt presented AP death Level 3; and Ukraine, United Kingdom, and Japan presented AP death Level 4 (Figure 4a,b).

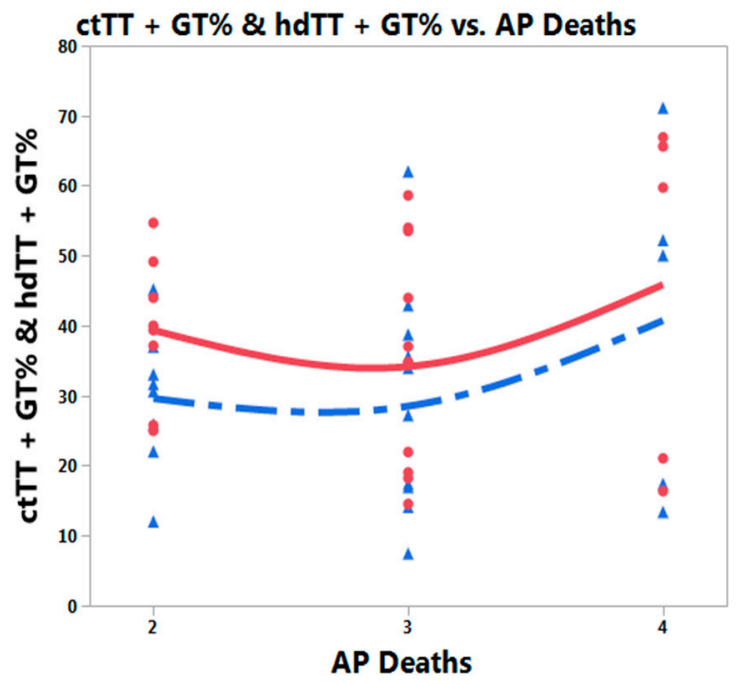

(a)

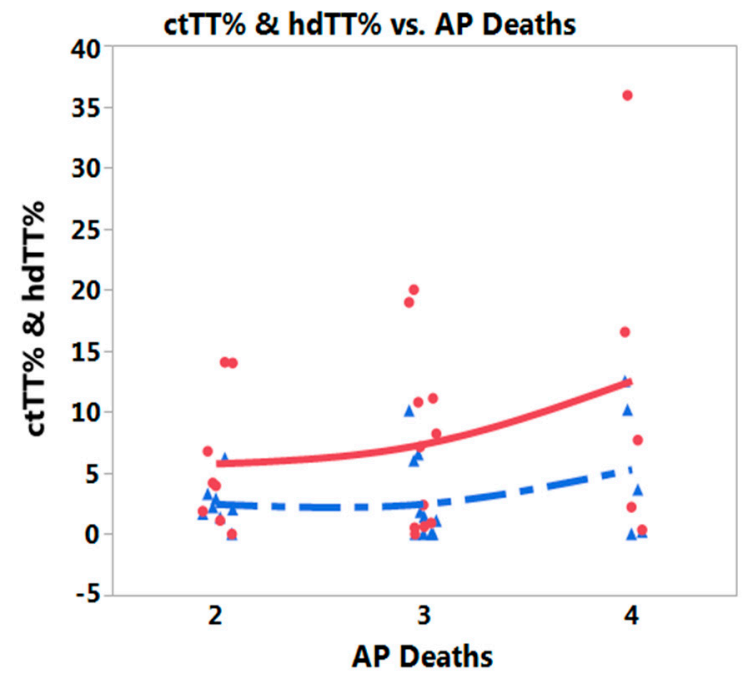

(b)

Figure 4. Nonlinear fit of NOS3 G894T polymorphisms with death from air pollution bi-variate plots for countries with pooled RR > 2: (a) TT plus GT polymorphisms, (b) TT only (AP death: Death rates from air pollution, Levels per million: $2=51-100,3=101-250,4=251-400$ and greater); case $=$ red (solid line), control = blue (dotted line).

\section{Discussion}

Our meta-analysis represents the most comprehensive study focusing on the association between NOS3 894 polymorphisms and the risk of IHD to date, integrating air pollution data to explore the source of heterogeneity across the world's regions. We conducted meta-prediction analyses to examine the potential impact of air pollution on the link between NOS3 polymorphisms and IHD risks. Although theoretically there is a potential risk of ecological fallacy, the use of global data was necessary because large-scale individual data is not available. Tools for monitoring the amount of pollutant absorbed by an individual with the individual's biophysical characteristics and the space-time activities are in development, however the use of such are not prevalent across countries [77]. Although 
meta-regression is frequently used for meta-prediction in advanced meta-analysis [63], it is important to point out that as a linear model, regression analysis is unable to detect nonlinear patterns. Furthermore, critiques of linear modeling, including Pearson's correlation and regression, reported issues being overly simplistic; nonlinear modeling is more appropriate when the underlying data structure is nonlinear, such as the relationship between air pollution and death [78-80]. Because AIC or AICc does not necessarily change with the addition of variables and instead varies based upon the composition of the predictors, it is more likely to yield an optimal model [74]. As such, the use of multiple meta-analytics was not only helpful to verify the results across the analytics, but also to visually detect regional geographical patterns.

NOS3 affects metabolism in the urea cycle of the methylation pathway, critical for preventing systemic inflammation. Vascular effects of oxidative stress resulted from air pollution are mediated by NOS which is reduced in the presence of the NOS3 894 T polymorphisms [15] leading to endothelial dysfunction [79]. Thus, airborne exposure to ambient PM is a major cardiovascular health threat. In 2016, of the 4.1 million deaths attributed to PM2.5 exposure, most (58\%) were IHD and stroke [81]. Because airborne PM has the capacity to generate oxygen free radicals, PM exposure may trigger a systemic inflammatory effect through oxidative stress mechanisms [80]. Changes in the expression of genes related to oxidative stress pathways have been shown to be differentially regulated by PM exposure [82]; thus, PM has the capacity to induce a pro-inflammatory phenotype consistent with vascular disease progression [83]. Because air pollution may compromise methylation pathways to increase systemic inflammation, high risk groups with polymorphisms in the methylation pathways are more vulnerable to develop health problems. Therefore, a better understanding of possible connections between environmental pollution, NOS3 polymorphisms, and IHD can be useful in developing potential prevention strategies. Further studies are needed to examine the complexity of the associations among NOS3 gene polymorphisms per population stratifications within the countries with accurate measurement of exposure to air pollution in relation to geographic location across time, and disease risk.

Our meta-predictive analysis demonstrated an upward trend in air pollution death rate level associated with the NOS3 894 TT homozygous genotype for countries with a RR greater than 2. While our findings were not significant, this trend is consistent with the emerging pattern of association of air pollution with gene polymorphisms and disease risk [30-47]. Previous studies have found significantly increased polymorphisms of the MTHFR gene with increased air pollution levels in various conditions including colorectal cancer, breast cancer, leukemia, Alzheimer's disease, and hypertensive disorders during pregnancy (HDP) [30,31,33-35], and increased disease risk for HDP [35]. Although the MTHFR gene is known to be heat sensitive [84,85], there is no current evidence of heat sensitivity related to the NOS3 mechanism; however, the trend of increased NOS3 polymorphisms with increased air pollution for countries with higher risk $(R R>2)$ is consistent with each of these previous studies [30,31,33-35]. In the global context, Asian countries tended to have higher air pollution death rates in recent years but did not yet demonstrate an associated increase in NOS3 polymorphisms; however, Asian countries presented with higher IHD risk in association with NOS3 894 polymorphisms.

Our analysis revealed significant associations between NOS3 894 TT and GT (polymorphisms with IHD risk across all racial-ethnic populations), whereas the common allele NOS3 GG genotype was observed to be protective for all groups. The $\mathrm{T}$ allele was associated with an increased risk of IHD for all groups, and, consistent with reports from previous meta-analyses, suggests those carrying the NOS3 894 T allele may have a predisposed risk for IHD [12,17-21]. It is important to point out that upon subgroup analyses, 10 countries (Ukraine, the United Kingdom, Brazil, Chile, Japan, South Korea, India, Iran, Egypt and Morocco) demonstrated an average RR greater than 2, which presented the NOS3 894 TT polymorphism genotype as a potentially causal factor of IHD as a biological marker based on the criteria for strong evidence used in international consensus panels [59,60]. For these countries, meta-predictive analysis demonstrated an increasing trend in air pollution association with increased NOS3 894 polymorphisms. 
Heterogeneity with regional differences on polymorphism rates and IHD risk was demonstrated by the data. Congruent with our study, others have also identified ethnicity as the source of heterogeneity in the association between NOS3 894 polymorphism and MI risk among Asians vs. non-Asians [18]. Mechanistic studies have shown the impact of NOS3 894 polymorphisms on IHD risks could undergo several potential pathways (e.g., reduced $\mathrm{NO}$ level, increased oxidative stress, impaired endothelial function, and increased vascular inflammation) in Asian populations [86,87]. There is also evidence demonstrating significant associations between NOS3 894 polymorphisms and two leading risk factors of IHD, hypertension and type 2 diabetes in Asians [88-91]. Additional factors including age, gender and PM concentration may also play a role in gene-environment interaction among Asians through oxidative stress pathways [92,93]. Additional studies including large scale sample size and samples from various race/ethnic groups are needed to explain the different mechanisms contributing the impact of NOS3 894 on IHD risk among various ethnic groups/regions.

\section{Conclusions}

The results of our comprehensive meta-predictive analysis demonstrated differences in the rate of NOS3 894 polymorphisms and associated IHD risk across global populations. This analysis revealed a trend in the association between increased air pollution associated death rates with increased NOS3 894 polymorphisms. These findings provide novel insight regarding the association between NOS3 894 polymorphisms, air pollution, and IHD risk. Both homozygous TT and heterozygous GT genotypes of NOS3 894 in Caucasian populations were found to be higher than in other populations including African, Hispanic, Middle Eastern, South Asian and East Asian. However, both homozygous and heterozygous NOS3 894 polymorphism-associated IHD risks are higher in Asian nations when compared to other nations. Future studies exploring epigenetic factors in association with NOS3 894 polymorphisms and IHD and prevention strategies for IHD are needed.

Supplementary Materials: The following are available online at http:/ / www.mdpi.com/2305-6304/6/3/44/s1, Table S1: Characteristics of included studies on NOS3 894 Genotypes, Table S2: Pooled meta-analysis: NOS3 G894T genotypes and risk for ischemic heart disease (IHD) by subgroups, Figure S1: Ranked \% NOS3 homozygous TT and heterozygous GT for groups of control $(n=12,222)$ and ischemic heart disease $(n=16,219)$ from 61 study groups per country-race (number of study groups) and sample size, Figure S2: Forest plot for the meta-analysis of the associations between the NOS3 TT genotype and ischemic heart disease (IHD) for RR > 1-2, Figure S3: Forest plot for the meta-analysis of the associations between the NOS3 TT genotype and ischemic heart disease (IHD) for RR < 1, Figure S4: Geographical information map for \% NOS3 GT and TT genotypes per control and ischemic heart disease (IHD) groups, and IHD risk, Figure S5: Geographical information map for \% NOS3 GT genotype per control and ischemic heart disease (IHD) groups, and IHD risk, Figure S6: Nonlinear fit of NOS3 G894T TT with death from air pollution for (a) all countries and (b) countries with pooled RR $>2$.

Author Contributions: Conceived the concepts and study design: S.P.K.S.; acquisition and search of the literature: R.J., F.D., and N.T.C.; data entry and verification of data accuracy: R.J., L.Y., F.D., and N.T.C.; analysis and interpretation of data: S.P.K.S., R.J., Z.F.C. and C.H.Y.; wrote the first draft of the manuscript: all authors. Agreed with manuscript results and conclusions: all authors reviewed and approved the final manuscript, ensuring integrity and accuracy.

Acknowledgments: Software programs used in this study have been supported in part by the Augusta University, College of Nursing Research Startup Fund, awarded to the corresponding author.

Conflicts of Interest: The authors declare that there are no conflicts of interest associated with the manuscript.

\section{References}

1. Ferguson, J.F.; Phillips, C.M.; McMonagle, J.; Pérez-Martínez, P.; Shaw, D.I.; Lovegrove, J.A.; Roche, H.M. NOS3 gene polymorphisms are associated with risk markers of cardiovascular disease, and interact with omega-3 polyunsaturated fatty acids. Atherosclerosis 2010, 211, 539-544. [CrossRef] [PubMed]

2. Jaramillo, P.C.; Munoz, M.A.; Lanas, M.C.; Lanas, Z.F.; Salazar, I.A. Endothelial nitric oxide synthase G894T gene polymorphism in Chilean subjects with coronary artery disease and controls. Clin. Chim. Acta 2006, 371, 102-106. [CrossRef] [PubMed]

3. World Health Organization. Cardiovascular Diseases. Available online: http://www.who.int/ cardiovasculardiseases/en/ (accessed on 1 March 2018). 
4. Center for Disease Control and Prevention. Heart Disease Facts. Available online: https://www.cdc.gov/ heartdisease/facts.htm (accessed on 1 March 2018).

5. Heidenreich, P.A.; Trogdon, J.G.; Khavjou, O.A.; Butler, J.; Dracup, K.; Ezekowitz, M.D.; Woo, Y.J. Forecasting the future of cardiovascular disease in the United States: A policy statement from the American Heart Association. Circulation 2011, 123, 933-944. [CrossRef] [PubMed]

6. American Heart Association. Cardiovascular Disease: A Costly Burden for Americans. Available online: http:/ / www.heart.org/idc/groups/heart-public/@wcm/@adv/documents/downloadable/ucm 491543.pdf (accessed on 1 March 2018).

7. Arnett, D.K.; Baird, A.E.; Barkley, R.A.; Basson, C.T.; Boerwinkle, E.; Ganesh, S.K.; O’Donnell, C.J. Relevance of genetics and genomics for prevention and treatment of cardiovascular disease: A scientific statement from the American Heart Association council on epidemiology and prevention, the stroke council, and the functional genomics and translational biology interdisciplinary working group. Circulation 2007, 115, 2878-2901. [CrossRef] [PubMed]

8. Gluba, A.; Banach, M.; Rysz, J.; Piotrowski, G.; Fendler, W.; Pietrucha, T. Is polymorphism within eNOS gene associated with the late onset of myocardial infarction? A pilot study. Angiology 2009, 60, 588-595. [CrossRef] [PubMed]

9. Colombo, M.G.; Andreassi, M.G.; Paradossi, U.; Botto, N.; Manfredi, S.; Masetti, S.; Biagini, A. Evidence for association of a common variant of the endothelial nitric oxide synthase gene (Glu298Asp polymorphism) to the presence, extent, and severity of coronary artery disease. Heart 2002, 82, 525-528. [CrossRef]

10. Gardemann, A.; Lohre, J.; Cayci, S.; Katz, N.; Tillmanns, H.; Haberbosch, W. The T allele of the missense Glu298Asp endothelial nitric oxide synthase gene polymorphism is associated with coronary heart disease in younger individuals with high atherosclerotic risk profile. Atherosclerosis 2002, 160, 167-175. [CrossRef]

11. Hingorani, A.D.; Liang, C.F.; Fatibene, J.; Lyon, A.; Monteith, S.; Parson, A.; Brown, M.J. A common variant of the endothelial nitric oxide synthase (Glu298->Asp) is a major risk factor for coronary artery disease in the UK. Circulation 1999, 100, 1515-1520. [CrossRef] [PubMed]

12. Rai, H.; Parveen, F.; Kumar, S.; Kapoor, A.; Sinha, N. Association of endothelial nitric oxide synthase gene polymorphisms with coronary artery disease: An updated meta-analysis and systematic review. PLoS ONE 2009, 9, e113363. [CrossRef] [PubMed]

13. Sheweita, S.A.; Baghdadi, H.; Allam, A.R. Role of genetic changes in the progression of cardiovascular diseases. Int. J. Biomed. Sci. 2011, 7, 238-248. [PubMed]

14. Gorchakova, O.; Koch, W.; von Beckerath, N.; Mehilli, J.; Schömig, A.; Kastrati, A. Association of a genetic variant of endothelial nitric oxide synthase with the 1 year clinical outcome after coronary stent placement. Eur. Heart J. 2003, 9, 820-827. [CrossRef]

15. Pereira, T.V.; Rudnicki, M.; Cheung, B.M.Y.; Baum, L.; Yamada, Y.; Oliveira, P.S.L.; Krieger, J.E. Three endothelial nitric oxide (NOS3) gene polymorphisms in hypertensive and normotensive individuals: Meta-analysis of 53 studies reveals evidence of publication bias. J. Hypertens. 2007, 25, 1763-1774. [CrossRef] [PubMed]

16. Joshi, M.S.; Mineo, C.; Shaul, P.W.; Bauer, J.A. Biochemical consequences of the NOS3 Glu298Asp variation in human endothelium: Altered caveolar localization and impaired response to shear. FASEB J. 2007, 21, 2655-2663. [CrossRef] [PubMed]

17. Yang, Y.; Du, K.; Liu, Z.; Lu, X. Endothelial nitric oxide synthase (eNOS) 4b/a gene polymorphisms and coronary artery disease: Evidence from a meta-analysis. Int. J. Mol. Sci. 2014, 7, 7987-8003. [CrossRef] [PubMed]

18. Luo, J.Q.; Wen, J.G.; Zhou, H.H.; Chen, X.P.; Zhang, W. Endothelial nitric oxide synthase gene G894T polymorphism and myocardial infarction: A meta-analysis of 34 studies involving 21068 subjects. PLoS ONE 2014, 9, e87196. [CrossRef] [PubMed]

19. Casas, J.P.; Bautista, L.E.; Humphries, S.E.; Hingorani, A.D. Endothelial nitric oxide synthase genotype and ischemic heart disease: meta-analysis of 26 studies involving 23028 subjects. Circulation 2004, 109, 1359-1365. [CrossRef] [PubMed]

20. Wang, Q.Q.; Yu, L.; Huang, G.R.; Zhang, L.; Liu, Y.Q.; Wang, T.W.; Xiong, H.Y. Polymorphisms of angiotensin converting enzyme and nitric oxide synthase 3 genes risk factors of high altitude pulmonary edema: A case-control study and meta-analysis. Tohoku J. Exp. Med. 2013, 229, 255-266. [CrossRef] [PubMed] 
21. Zhang, K.; Bai, P.; Shi, S.; Zhou, B.; Wang, Y.; Song, Y.; Rao, L.; Zhang, L. The G894T polymorphism on endothelial nitric oxide synthase gene is associated with increased coronary heart disease among Asia population: Evidence from a Meta analysis. Thromb. Res. 2012, 130, 192-197. [CrossRef] [PubMed]

22. Du, Y.; Xu, X.; Chu, M.; Guo, Y.; Wang, J. Air particulate matter and cardiovascular disease: The epidemiological, biomedical and clinical evidence. J. Thorac. Dis. 2016, 8, E8-E19. [CrossRef] [PubMed]

23. Pope, C.; Ezzati, M.; Dockery, D.W. Fine-particulate air pollution and life expectancy in the United States. N. Engl. J. Med. 2009, 360, 376-386. [CrossRef] [PubMed]

24. Zanobetti, A.; Schwartz, J. Particulate air pollution, progression, and survival after myocardial infarction. Environ. Health Perspect. 2007, 115, 769-775. [CrossRef] [PubMed]

25. Krewski, D. Evaluating the effects of ambient air pollution on life expectancy. N. Engl. J. Med. 2009, 360, 413-415. [CrossRef] [PubMed]

26. Rich, D.Q.; Schwartz, J.; Mittleman, M.A.; Link, M.; Luttmann-Gibson, H.; Catalano, P.J.; Dockery, D.W. Association of short-term ambient air pollution concentrations and ventricular arrhythmias. Am. J. Epidemiol. 2005, 161, 1123-1132. [CrossRef] [PubMed]

27. Dominici, F.; Peng, R.D.; Bell, M.L.; Pham, L.; McDermott, A.; Zeger, S.L.; Samet, J.M. Fine particulate air pollution and hospital admission for cardiovascular and respiratory diseases. JAMA 2006, 295, 1127-1134. [CrossRef] [PubMed]

28. Baccarelli, A.; Cassano, P.A.; Litonjua, A.; Park, S.K.; Suh, H.; Sparrow, D.; Vokonas, P.; Schwartz, J. Cardiac autonomic dysfunction: Effects from particulate air pollution and protection by dietary methyl nutrients and metabolic polymorphisms. Circulation 2008, 117, 1802-1809. [CrossRef] [PubMed]

29. Raaschou-Nielsen, O.; Andersen, Z.J.; Jensen, S.S.; Ketzel, M.; Sorensen, M.; Hansen, J.; Overvad, K. Traffic air pollution and mortality from cardiovascular disease and all causes: A Danish cohort study. Environ. Health 2012, 11, 60. [CrossRef] [PubMed]

30. Shiao, S.; Yu, C. Meta-prediction of MTHFR gene polymorphism mutations and associated risk for colorectal cancer. Biol. Res. Nurs. 2016, 18, 357-369. [CrossRef] [PubMed]

31. Wu, S.; Chen, Z.; Young, L.; Shiao, P.S. Meta-prediction of the effect of methylenetetrahydrofolate reductase polymorphisms and air pollution on Alzheimer's disease risk. Int. J. Environ. Res. Public Health 2017, 14, 63. [CrossRef] [PubMed]

32. Lin, Y.C.; Nunez, V.; Johns, R.; Shiao, P.S. APOA5 gene polymorphisms and cardiovascular diseases metaprediction in global populations. Nurs. Res. 2017, 66, 164-174. [CrossRef] [PubMed]

33. Gonzales, M.C.; Yu, P.; Shiao, S.P.K. MTHFR gene polymorphism-mutations and air pollution as risk factors for breast cancer: A metaprediction study. Nurs. Res. 2017, 66, 152-163. [CrossRef] [PubMed]

34. Lien, S.-Y.A.; Young, L.; Gau, B.-S.; Shiao, S.P. Meta-prediction of MTHFR gene polymorphism-mutations, air pollution, and risks of leukemia among world populations. Oncotarget 2017, 8, 4387-4398. [CrossRef] [PubMed]

35. Yang, Y.L.; Yang, H.L.; Shiao, S.P. Meta-prediction of MTHFR gene polymorphisms and air pollution on the risk of hypertensive disorders in pregnancy worldwide. Int. J. Environ. Res. Public Health 2018, 15, 326. [CrossRef] [PubMed]

36. Zanobetti, A.; Baccarelli, A.; Schwartz, J. Gene-air pollution interaction and cardiovascular disease: A review. Prog. Cardiovasc. Dis. 2011, 53, 344-352. [CrossRef] [PubMed]

37. Kim, K.N.; Kim, J.H.; Jung, K.; Hong, Y.C. Associations of air pollution exposure with blood pressure and heart rate variability are modified by oxidative stress genes: A repeated-measures panel among elderly urban residents. Environ. Health 2016, 15, 47. [CrossRef] [PubMed]

38. Fiordelisi, A.; Piscitelli, P.; Trimarco, B.; Coscion, E.; Iaccarino, G.; Sorriento, D. The mechanisms of air pollution and particulate matter in cardiovascular diseases. Heart Fail. Rev. 2017, 22, 337-347. [CrossRef] [PubMed]

39. Peters, A.; Schneider, A.; Greven, S.; Bellander, T.; Forastiere, F.; Ibald-Mulli, A.; Sunyer, J. Air pollution and inflammatory response in myocardial infarction survivors: Gene-environment interactions in a high-risk group. Inhal. Toxicol. 2007, 19, 161-175. [CrossRef] [PubMed]

40. Ren, C.; Park, S.K.; Vokonas, P.S.; Sparrow, D.; Wilker, E.; Baccarelli, A.; Suh, H.H.; Tucker, K.L.; Wright, R.O.; Schwartz, J. Air pollution and homocysteine: More evidence that oxidative stress-related genes modify effects of particulate air pollution. Epidemiology 2010, 21, 198-206. [CrossRef] [PubMed] 
41. Muto, E.; Hayashi, T.; Yamada, K.; Esaki, T.; Sagai, M.; Iguchi, A. Endothelial-constitutive nitric oxide synthase exists in airways and diesel exhaust particles inhibit the effect of nitric oxide. Life Sci. 1996, 59, 1563-1570. [CrossRef]

42. Sun, Q.H.; Yue, P.B.; Ying, Z.K.; Cardounel, A.J.; Brook, R.D.; Devlin, R.; Rajagopalan, S. Air pollution exposure potentiates hypertension through reactive oxygen species-mediated activation of Rho/ROCK. Arterioscler. Thromb. Vasc. Biol. 2008, 28, 1760-1766. [CrossRef] [PubMed]

43. Panasevich, S.; Leander, K.; Ljungman, P.; Bellander, T.; de Faire, U.; Pershagen, G.; Nyberg, F. Interaction between air pollution exposure and genes in relation to levels of inflammatory markers and risk of myocardial infarction. BMJ Open 2013, 3, e003058. [CrossRef] [PubMed]

44. Rochette, L.; Lorin, J.; Zeller, M.; Guilland, J.C.; Lorgis, L.; Cottin, Y.; Vergely, C. Nitric oxide synthase inhibition and oxidative stress in cardiovascular diseases: Possible therapeutic targets? Pharmacol. Ther. 2013, 140, 239-257. [CrossRef] [PubMed]

45. Luiking, Y.C.; Ten Have, G.A.; Wolfe, R.R.; Deutz, N.E. Arginine de novo and nitric oxide production in disease states. Am. J. Physiol. Endocrinol. Metab. 2012, 303, E1177-E1189. [CrossRef] [PubMed]

46. Wolters, M.; Ströhle, A.; Hahn, A. Age-associated changes in the metabolism of vitamin B12 and folic acid: Prevalence, aetiopathogenesis and pathophysiological consequences. Z. Gerontol. Geriatr. 2004, 37, 109-135. [CrossRef] [PubMed]

47. Bonnot, O.; Klünemann, H.H.; Sede, F.; Tordjman, S.; Cohen, D.; Walterfang, M. Diagnostic and treatment implications of psychosis secondary to treatable metabolic disorders in adults: A systematic review. Orphanet J. Rare Dis. 2014, 28, 65. [CrossRef] [PubMed]

48. Moher, D.; Cook, D.J.; Eastwood, S.; Olkin, I.; Rennie, D.; Stroup, D.F. Improving the quality of reports of meta-analyses of randomized controlled trials: The quorom statement. Onkologie 2000, 23, 597-602. [CrossRef] [PubMed]

49. Downs, S.H.; Black, N. The feasibility of creating a checklist for the assessment of the methodological quality both of randomized and non-randomized studies of health care interventions. J. Epidemiol. Health 1998, 52, 377-384. [CrossRef]

50. Stroup, D.F.; Berlin, J.A.; Morton, S.C.; Olkin, I.; Williamson, G.D.; Rennie, D.; Moher, D.; Becker, B.J.; Sipe, T.A.; Thacker, S.B. Meta-analysis of observational studies in epidemiology: A proposal for reporting. Meta-analysis of observational studies in epidemiology (moose) group. JAMA 2000, 283, 2008-2012. [CrossRef] [PubMed]

51. US Environmental Protection Agency. Air Quality Index. Available online: http:/ /www.airnow.gov/index. cfm?action=aqibasics.aqi (accessed on 8 December 2017).

52. Kenworthy, J.; Laube, F. Urban transport patterns in a global sample of cities and their linkages to transport infrastructure, land use, economics and environment. World Transp. Policy Pract. 2002, 8, 5-19.

53. World Health Organization. Deaths Attributable to Urban Air Pollution. 2004. Available online: http: / / www.who.int/heli/risks/urban/en/uapmap.1.pdf?ua=1 (accessed on 8 December 2017).

54. World Health Organization. Global Health Risks: Mortality and Burden of Disease Attributable to Selected Major Risks. 2009. Available online: http://www.who.int/healthinfo/global_burden_disease/ GlobalHealthRisks_report_full.pdf (accessed on 8 December 2017).

55. World Health Organization. Global Health Risks: Deaths from Air Pollution. 2012. Available online: https:/ / commons.wikimedia.org/wiki/File:Deathsfrom_air_pollution.png (accessed on 8 December 2017).

56. World Health Organization. The Urban Environment: A General Directory of Resources. 2015. Available online: http:/ / www.who.int/heli/risks/urban/urbenvdirectory/en/ (accessed on 8 December 2017).

57. Sha, Q.; Zhang, S. A test of Hardy-Weinberg equilibrium in structured populations. Genet. Epidemiol. 2011, 35, 671-678. [CrossRef] [PubMed]

58. Wittke-Thompson, J.K.; Pluzhnikov, A.; Cox, N.J. Rational inferences about departures from Hardy-Weinberg equilibrium. Am. J. Hum. Genet. 2005, 76, 967-986. [CrossRef] [PubMed]

59. How AICR Recommendations Cuts Colorectal Cancer Risk for Both Men and Women. Available online: http:/ / www.aicr.org/cancer-research-update/2016/11_02/cru-how-AICR-recommendations-cutscolorectal-cancer-risk-for-men-and-women.html (accessed on 16 March 2018).

60. WCRF-AICR Continuous Update Project. Diet, Nutrition, Physical Activity and Colorectal Cancer. 2017. Available online: http:/ / www.aicr.org/continuous-update-project/reports/colorectal-cancer-2017-report. pdf (accessed on 1 July 2018). 
61. Viera, A.J. Odds ratios and risk ratios: What's the difference and why does it matter? South. Med. J. 2008, 101, 730-734. [CrossRef] [PubMed]

62. Scott, I. Interpreting risks and ratios in therapy trials. Aust. Prescr. 2008, 31, 12-16. [CrossRef]

63. Deeks, J.J.; Higgins, J.; Altman, D.G. Analysing Data and Undertaking Meta-Analyses. In Cochrane Handbook for Systematic Reviews of Interventions; Higgins, J., Green, S., Eds.; Wiley-Blackwell: Hoboken, NJ, USA, 2008; pp. 243-296.

64. Albrecht, J. Key Concepts and Techniques in GIS; Sage: Thousand Oaks, CA, USA, 2007.

65. Pereira, C.; Denise, A.; Lespinet, O. A meta-approach for improving the prediction and the functional annotation of ortholog groups. BMC Genom. 2014, 15 (Suppl. 6), S16. [CrossRef] [PubMed]

66. Strobl, C.; Malley, J.; Tutz, G. An introduction to recursive partitioning: Rationale, application, and characteristics of classification and regression trees, bagging, and random forests. Psychol. Methods 2009, 14, 323-348. [CrossRef] [PubMed]

67. Tam, W.W.; Wong, T.W.; Wong, A.H.; Hui, D.S. Effect of dust storm events on daily emergency admissions for respiratory diseases. Respirology 2012, 17, 143-148. [CrossRef] [PubMed]

68. Lai, L. Public health risks of prolonged fine particle events associated with stagnation and air quality index based on fine particle matter with a diameter $<2.5 \mu \mathrm{m}$ in the Kaoping region of Taiwan. Int. J. Biometeorol. 2016, 60, 1907-1917. [CrossRef]

69. Abdi, H.; Williams, L.J. Tukey's honesty significant difference (HSD) test. In Encyclopedia of Research Design; Salkind, N., Ed.; Sage: Thousand Oaks, CA, USA, 2010; pp. 1565-1570.

70. Mao, W. Leave-one-out cross-validation-based model selection for multi-input multi-output support vector machine. Neural Comput. Appl. 2014, 24, 441-451. [CrossRef]

71. Yu, C.H. Exploratory data analysis in the context of data mining and resampling. Int. J. Psychol. Res. 2010, 3, 9-22. [CrossRef]

72. Yu, C.H. Dancing with the Data: The Art and Science of Data Visualization; LAP: Saarbrucken, Germany, 2014.

73. Cook, E.F.; Goldman, L. Empiric comparison of multivariate analytic techniques: Advantages and disadvantages of recursive partitioning analysis. J. Chronic Dis. 1984, 37, 721-731. [CrossRef]

74. Kattan, M.W.; Hess, K.R.; Beck, J.R. Experiments to determine whether recursive partitioning (CART) or an artificial neural network overcomes theoretical limitations of Cox proportional hazards regression. Comput. Biomed. Res. 1998, 31, 363-373. [CrossRef] [PubMed]

75. Akaike, H. Prediction and entropy. In A Celebration of Statistics; Atkinson, A.C., Fienberg, S.E., Eds.; Springer: New York, NY, USA, 1985; pp. 1-24.

76. Faraway, J.J. Extending the Linear Model with $r$ (Texts in Statistical Science); Chapman \& Hall/CRC: New York, NY, USA, 2005.

77. Lu, Y.; Fang, T.B. Examining personal air pollution exposure, intake, and health danger zone using time geography and 3D geovisualization. ISPRS Int. J. Geo-Inf. 2014, 4, 32-46. [CrossRef]

78. Packard, G. On the use of log-transformation vs. nonlinear regression for analyzing biological power laws. Biol. J. Linn. Soc. 2014, 113, 1167-1178. [CrossRef]

79. Xiao, X.; White, E.P.; Hooten, M.B.; Durham, S.L. On the use of log-transformation vs. nonlinear regression for analyzing biological power laws. Ecology 2011, 92, 1887-1894. [CrossRef] [PubMed]

80. Yu, C.H.; Lee, H.S.; Gan, S.; Brown, E. Nonlinear modeling with big data in SAS and JMP. In Proceedings of the Western Users of SAS Software Conference (paper presented), Long Beach, CA, USA, 22 September 2017.

81. Health Effects Institute. State of Global Air 2018 Special Report. Health Effects Institute: Boston, MA. Available online: https:/ / www.stateofglobalair.org/sites/default/ files/soga-2018-report.pdf (accessed on 21 April 2018).

82. Miller, M.; Shaw, C.; Langrish, J. From particles to patients: Oxidative stress and the cardiovascular effects of air pollution. Future Cardiol. 2012, 8, 577-602. [CrossRef] [PubMed]

83. Xu, M.; Guo, Y.; Zhang, Y.; Westerdahl, D.; Mo, Y.; Liang, F.; Pan, X. Spatiotemporal analysis of particulate air pollution and ischemic heart disease mortality in Beijing, China. Environ. Health 2014, 13, 109. [CrossRef] [PubMed]

84. Kang, S.S.; Zhou, J.; Wong, P.W.; Kowalisyn, J.; Strokosch, G. Intermediate homocysteinemia: A thermolabile variant of methylenetetrahydrofolate reductase. Am. J. Hum. Genet. 1998, 43, 414-421. 
85. Leclerc, D.; Sibani, S.; Rozen, R. Molecular biology of methylenetetrahydrofolate reductase (MTHFR) and overview of mutations/polymorphisms. In Madame Curie Bioscience Database; Landes Bioscience: Austin, TX, USA, 2000. Available online: http:/ / www.ncbi.nlm.nih.gov/books/NBK6561/ (accessed on 29 May 2018).

86. Mahmoodi, K.; Nasehi, L.; Karami, E.; Soltanpour, M.S. Association of nitric oxide levels and endothelial nitric oxide synthase G894T polymorphism with coronary artery disease in the Iranian population. Vasc. Specialist Int. 2016, 32, 105. [CrossRef] [PubMed]

87. Hsieh, M.C.; Hsiao, J.Y.; Tien, K.J.; Chang, S.J.; Lin, P.C.; Hsu, S.C.; Lin, S.R. The association of endothelial nitric oxide synthase G894T polymorphism with C-reactive protein level and metabolic syndrome in a Chinese study group. Metabolism 2008, 57, 1125-1129. [CrossRef] [PubMed]

88. Mackawy, A.M.; Khan, A.A.; Badawy, M.E. Association of the endothelial nitric oxide synthase gene G894T polymorphism with the risk of diabetic nephropathy in Qassim region, Saudi Arabia-A pilot study. Meta Gene 2014, 2, 392-402. [CrossRef] [PubMed]

89. Li, Y.Y. Endothelial nitric oxide synthase G894T gene polymorphism and essential hypertension in the Chinese population: A meta-analysis involving 11,248 subjects. Intern. Med. 2011, 50, 2099-2106. [PubMed]

90. Angeline, T.; Krithiga, H.R.; Isabel, W.; Asirvatham, A.J.; Poornima, A. Endothelial nitric oxide synthase gene polymorphism (G894T) and diabetes mellitus (type II) among South Indians. Oxid. Med. Cell. Longev. 2011, 2011, 1-4. [CrossRef] [PubMed]

91. Tso, A.W.; Tan, K.C.; Wat, N.M.; Janus, E.D.; Lam, T.H.; Lam, K.S. Endothelial nitric oxide synthase G894T (Glu298Asp) polymorphism was predictive of glycemic status in a 5-year prospective study of Chinese subjects with impaired glucose tolerance. Metabolism 2006, 55, 1155-1158. [CrossRef] [PubMed]

92. Chang, J.; Li, B.; Li, J.; Sun, Y. The Effects of Age, Period, and Cohort on Mortality from Ischemic Heart Disease in China. Int. J. Environ. Res. Public Health 2017, 14, 50. [CrossRef] [PubMed]

93. Xu, A.; Mu, Z.; Jiang, B.; Wang, W.; Yu, H.; Zhang, L.; Li, J. Acute effects of particulate air pollution on ischemic heart disease hospitalizations in Shanghai, China. Int. J. Environ. Res. Public Health 2017, 14, 168. [CrossRef] [PubMed]

(C) 2018 by the authors. Licensee MDPI, Basel, Switzerland. This article is an open access article distributed under the terms and conditions of the Creative Commons Attribution (CC BY) license (http://creativecommons.org/licenses/by/4.0/). 